\title{
Development and Validation of a UPLC-ESI-MS Method for Quantitation of the Anti-Alzheimer Drug Galantamine and other Amaryllidaceae Alkaloids in Plants
}

\author{
José R. de Paiva, ${ }^{a, b}$ Ana S. Q. Souza, ${ }^{a, c}$ Rita C. A. Pereira, ${ }^{b}$ Paulo R. V. Ribeiro, ${ }^{b}$ \\ Guilherme J. Zocolo, ${ }^{\circledR b}$ Edy S. de Brito, ${ }^{\circledR b}$ Otília D. L. Pessoa ${ }^{\circledR a}$ and Kirley M. Canuto ${ }^{\circledR *, b}$ \\ ${ }^{a}$ Departamento de Química, Universidade Federal do Ceará, Campus do Pici, \\ 60451-970 Fortaleza-CE, Brazil \\ ${ }^{b}$ Embrapa Agroindústria Tropical, Rua Doutora Sara Mesquita, 2270, Pici, \\ 60511-110 Fortaleza-CE, Brazil
}

'Departamento de Farmácia, Universidade Federal do Ceará, 60430-160 Fortaleza-CE, Brazil

\begin{abstract}
Our study aimed at the development of a method based on ultra-performance liquid chromatography coupled to mass spectrometry (UPLC-ESI-MS) using selected ion monitoring for the simultaneous quantitation of the alkaloids galantamine, pseudolycorine, sanguinine and narciclasine in Amaryllidaceae species (Hippeastrum elegans, Habranthus cf. irwinianus, Hymenocallis littoralis and Griffinia nocturna). The alkaloids were extracted from dried and ground bulbs $(100 \mathrm{mg})$ using liquid-liquid microextraction followed by solid phase extraction in cation exchange cartridges. The quantification method showed good linearity (correlation coefficient, $R \geq 0.9968$ ) and selectivity for a run time of $10 \mathrm{~min}$. All values were within the acceptable limits for recovery (87.5-96.2\%), interday (coefficient of variation, CV\%, 1.3-8.4\%) and intraday precision (CV\% 5.7-8.1\%), except narciclasine (70\%). The limits of detection and quantification were 5-100 and 20-350 $\mathrm{ng} \mathrm{mL}^{-1}$, respectively. Our method demonstrated to be rapid, sensitive and reliable, therefore appropriate for being employed in the prospection of new source of galantamine and other alkaloids.
\end{abstract}

Keywords: galantamine, sanguinine, pseudolycorine, narciclasine, UPLC-ESI-MS

\section{Introduction}

Galantamine is one of the main drugs used for the clinical treatment of Alzheimer's disease, acting as a selective, reversible and competitive inhibitor of acetylcholinesterase. ${ }^{1}$ Furthermore, this compound has demonstrated efficacy against other psychiatric disorders such as schizophrenia, depression, bipolar disorders and chemical dependencies such as alcoholism and cocaine. ${ }^{2}$

Galantamine is a typical Amaryllidaceae alkaloid that has been reported in several genera. For medical purposes, this compound has been mainly extracted from Narcissus spp in Western Europe, Leucojum aestivum in Eastern Europe, Lycoris radiata in China and Ungernia victoria in Uzbekistan and Kazakhstan. ${ }^{3}$ Although the chemical synthesis of galantamine is well established, the yield achieved is still low and insufficient to meet the world

*e-mail: kirley.canuto@embrapa.br demand, therefore plants continue to be the main source of this natural product. ${ }^{4}$

Many analytical methods for the quantification of galantamine and other Amaryllidaceae alkaloid have been previously reported using gas chromatograph with flame ionization detector (GC-FID), ${ }^{5}$ gas chromatograph mass spectrometry (GC-MS), non-aqueous capillary electrophoresis (NACE), ${ }^{6}$ high-performance liquid chromatography with UV (HPLC-UV) ${ }^{7}$ and with diode array detector (HPLC-DAD), ${ }^{8}$ high performance thin layer chromatography (HPTLC) ${ }^{9}$ and high-performance liquid chromatography-diode array detector-tandem mass spectrometry (UPLC-DAD-MS/MS). ${ }^{10}$ Likewise, several extraction techniques for these plant alkaloids have been described, such as microwave,${ }^{10}$ ultrasound,${ }^{6}$ pressurized solvent, ${ }^{11}$ conventional maceration with organic solvent ${ }^{12}$ and ionic liquid. ${ }^{13}$ These techniques have showed efficiency but also some limitations. Nowadays, the main challenges for analysis of Amaryllidaceae alkaloid are to enhance the 
sensitivity of the analytical method aiming at the use of lower biomass amount, as well as to reduce the run time without affecting the resolution due to the huge number of isomeric and/or isobaric compounds. Therefore, the sample preparation has become a key-step for the improvement of the performance of the method for increasing its sensitivity and selectivity eliminating interfering compounds. In this regard, the use of solid-phase extraction (SPE) has yielded great advances and results. ${ }^{11,14}$

In spite of its higher cost, UPLC-MS has become popular in the last few years thanks to advantages such as high sensitivity, fastness, and broad applications. UPLC consists of an ultra-high pressure chromatographic system operating in a range of 6000-15000 psi equipped with a $1.7 \mu \mathrm{m}$ particles packed-column, therefore this method enables better resolution and shaper peak (greater signal-to-noise $(\mathrm{S} / \mathrm{N})$ ratio) in a shorter time. In addition, sensitivity is significantly enhanced when UPLC is hyphenated to a mass spectrometer-type detector. Furthermore, MS analysis provides more structural information on the chemical profile than the conventional chromatographic detectors, allowing for a more reliable identification. ${ }^{15}$ For quantitative MS analysis, the method of choice relies on tandem systems, mainly composed of triple quadrupole detectors, since higher sensitivity is achieved by monitoring specific ions transitions (the so-called multiple reaction monitoringMRM). This approach has been successfully employed for analyzing drugs such as galantamine in biological matrices. ${ }^{16}$ Alternatively, it is possible to filter the $\mathrm{m} / \mathrm{z}$ from a targetion employing a single MS detector. Indeed, this method known as SIM (selected ion monitoring) is not as sensitive as MRM, however, its cost-benefit makes it attractive for many applications. ${ }^{17}$ Our group has successfully employed this technique for quantifying lipopeptides, diterpenes and flavonoids. ${ }^{18,19}$

Our study aimed at the development and validation of a UPLC-ESI-MS method for simultaneous quantitation of galantamine along with three other Amarillydaceae alkaloids (sanguinine, pseudolycorine and narciclasine) by applying it to four representative species of this botanical family: Hippeastrum elegans, Habranthus irwinianus, Hymenocallis littoralis and Griffinia nocturna. Amarillydaceae alkaloids comprise over 500 compounds subdivided into 11 different skeletal types. Sanguinine is an $O$-desmethylgalantamine derivative whose acetylcholinesterase action has showed to be ten times greater than galantamine. ${ }^{20}$ Narciclasine is commonly found in Narcissus species and has demonstrated interesting pharmacological potential such as strong cytotoxic activity against several tumoral lines, anti-inflammatory and antiviral activities as well as anti-Alzheimer effect by decreasing the production of $\beta$-Amyloid plaques. ${ }^{21}$ Meanwhile, pseudolycorine is an opened dioxole ring derivative from lycorine, which has exhibited antitumoral activities in pre-clinical and in vitro experiments. ${ }^{20}$

\section{Experimental}

\section{Materials and methods}

\section{Chemicals and solvents}

The analytical standards galantamine and codeine- $d_{3}$ (98\% purity) were purchased from Sigma-Aldrich (Saint Louis, USA), while standards of pseudolycorine, sanguinine and narciclasine were isolated from $H$. elegans earlier (90-95\% purity) (Figure 1 and S1, Supplementary Information (SI) section). ${ }^{22}$ LC-MS grade acetonitrile and methanol, as well as HPLC hexane, were from Merck (Darmstadt, Germany). Formic acid was from ROE Scientific Inc. (Cincinnati, USA). Ammonium hydroxide $30 \%$ and sulfuric acid $96 \%$ were from Synth (São Paulo, Brazil). Ultra-pure water $\left(18.2 \mathrm{M} \Omega \mathrm{cm}\right.$ at $\left.25{ }^{\circ} \mathrm{C}\right)$ was obtained from a Milli-Q purification system (Millipore, Bedford, USA).
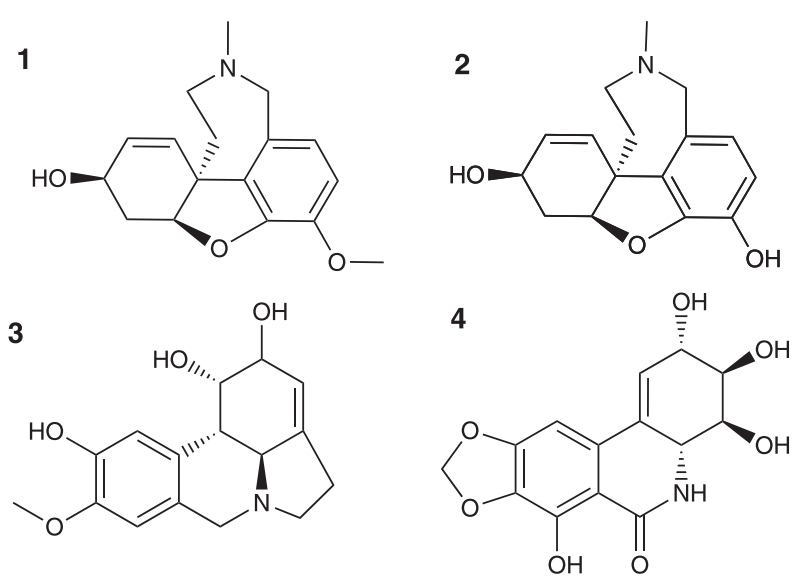

Figure 1. Chemical structures of four Amaryllidaceae alkaloids: galantamine (1), sanguinine (2), pseudolycorine (3) and narciclasine (4).

\section{Standards preparation}

Individual stock solutions $\left(100 \mu \mathrm{g} \mathrm{mL} \mathrm{m}^{-1}\right)$ of each alkaloid standard (based on their purity) were prepared by dissolving them directly in acetonitrile. Next, a mixed solution containing the four alkaloids was prepared at a concentration of $10 \mu \mathrm{g} \mathrm{mL} \mathrm{mL}^{-1}$, from which solutions for the calibration curve were prepared by a serial dilution with methanol. All solutions were stored in screw-top vials and stored in a freezer at $-80{ }^{\circ} \mathrm{C}$ until analysis. 
Ultra-performance liquid chromatography with quadrupole detector and selected ion monitoring (UPLC-QDA-SIM) analysis

Standards and samples were analyzed through an Acquity UPLC system fitted to QDa detector (Waters, Milford, USA). Chromatographic runs were accomplished on a BEH C18 column $(150 \mathrm{~mm} \times 2.1 \mathrm{~mm}, 1.7 \mu \mathrm{m})$ at $40{ }^{\circ} \mathrm{C}$, injecting $2 \mu \mathrm{L}$ of samples maintained at $20^{\circ} \mathrm{C}$. These conditions were chosen after testing column temperature $\left(30,40\right.$ and $\left.50{ }^{\circ} \mathrm{C}\right)$, sample temperature $\left(10\right.$ and $\left.20{ }^{\circ} \mathrm{C}\right)$ and injection volume ( 2 and $5 \mu \mathrm{L}$ ). The mobile phase was composed of $0.1 \%$ formic acid in water (A) and $0.1 \%$ formic acid in acetonitrile (B) at a flow rate of $0.4 \mathrm{~mL} \mathrm{~min}^{-1}$. The elution gradient varied from 2 to $33 \%$ of $\mathrm{B}(0-5.0 \mathrm{~min})$, increased immediately to $100 \%$ of B at 5.10 min and was kept until $7.0 \mathrm{~min}$, then it returned to $2 \%$ of $\mathrm{B}$ at $7.1 \mathrm{~min}$ for equilibrating the column until $10.5 \mathrm{~min}$. The mass spectra were acquired in the positive mode at a mass range between $\mathrm{m} / \mathrm{z}, 110$ and 1180 . The SIM mode method was established using these parameters: $\mathrm{N}_{2}$ desolvation gas $\left(600 \mathrm{~L} \mathrm{~h}^{-1}\right)$, extraction cone voltage of $15 \mathrm{~V}$ and capillary voltage of $0.8 \mathrm{kV}$. Samples were filtered through $0.22 \mu \mathrm{m}$ polytetrafluoroethylene (PTFE) membranes (Millipore ${ }^{\circledR}$, Darmstadt, Germany). The instrument was controlled by the software Empower 3. ${ }^{23}$ The $[\mathrm{M}+\mathrm{H}]^{+}$ions from the alkaloids were monitored according to these time intervals: $\mathrm{m} / \mathrm{z}, 299.10$ for pseudolycorine (1.4-2.4 $\mathrm{min}$ ), $\mathrm{m} / \mathrm{z}, 274.10$ for sanguinine (1.6-2.6 $\mathrm{min}), \mathrm{m} / \mathrm{z}, 288.10$ for galantamine (2.6-3.6 $\mathrm{min}$ ) and $\mathrm{m} / \mathrm{z}, 307.90$ for narciclasine (3.8-4.8 $\mathrm{min}$ ) (Table 1).

\section{Plant material}

The plant materials were harvested from an Amaryllidaceae collection grown in a greenhouse facility at Embrapa Agroindústria Tropical (Fortaleza, Ceará, Brazil) in November/2016: Hippeastrum elegans (syn.: Hippeastrum solandriflorum), Habranthus cf. irwinianus Ravenna, Arraias, Hymenocallis littoralis (Jacq.) Salisb, Griffinia nocturna Ravenna. A voucher specimen for H. elegans was deposited at Prisco Bezerra Herbarium in Universidade Federal do Ceará (No. 60762), while the others were at the herbarium of Embrapa Recursos Genéticos (ACA 50; MFS1712; GPS10892, respectively). After being harvested, plants were separated into roots, bulbs and leaves (when present). The bulbs were washed with distilled water to remove soil, weighed, cut into smaller pieces and dried at $40{ }^{\circ} \mathrm{C}$ in a drying oven with forced air circulation until constant weight was reached (7 days). The dried bulbs were ground in knife mills (particle size $<0.84 \mathrm{~mm}$ ), packed in plastic bags, sealed and stored at $20^{\circ} \mathrm{C}$ in a low humidity room until analysis.

\section{Extraction methods}

Three extraction methods were assessed in quintuplicate using $100 \mathrm{mg}$ of dried bulb powder from $\mathrm{H}$. elegans: (I) acid-base liquid-liquid partition (II) solid-liquid extraction and (III) solid-liquid extraction followed by solid-phase extraction. The method I was based on the literature..$^{24,25}$ Briefly, bulbs were deffated with $4 \mathrm{~mL}$ of hexane for $2 \mathrm{~h}$. After removal of the hexane, the plant material was extracted with $4 \mathrm{~mL}$ of alkaline methanol solution $(\mathrm{pH}=8.0$, adjusted with $\mathrm{NaOH} 1 \mathrm{M})$. Next, the methanolic solution was acidified to $\mathrm{pH}=2.0$ with $\mathrm{H}_{2} \mathrm{SO}_{4}$ $2 \%$ and partitioned with dichloromethane $(3 \times 2 \mathrm{~mL})$. Afterwards, the methanolic solution was alkalized to $\mathrm{pH}=10$ with $\mathrm{NH}_{4} \mathrm{OH}$ and partitioned with dichloromethane $(3 \times 2 \mathrm{~mL})$. The dichloromethane phase was dried and resuspended in $1 \mathrm{~mL}$ of methanol filtered and injected on the UPLC-ESI-MS chromatograph.

The method II consisted of a maceration with $4 \mathrm{~mL}$ of hexane for $20 \mathrm{~min}$ followed by a partition with $4 \mathrm{~mL}$ of a solution $\mathrm{MeOH}-\mathrm{H}_{2} \mathrm{O}-\mathrm{H}_{2} \mathrm{SO}_{4}\left(89: 10: 1, \mathrm{v} \mathrm{v}^{-1}\right)$. Then, an aliquot of $1 \mathrm{~mL}$ of this acid hydroalcoholic phase was filtered and analyzed. For the method III, an aliquot of $0.5 \mathrm{~mL}$ of the hydroalcoholic acid phase generated by method II was applied in a cation exchange SPE cartridge (Bond Elut SCX, Agilent, $100 \mathrm{mg}$ ). Briefly, SPE cartridge was preconditioned with $4 \mathrm{~mL}$ of water, followed by $2 \mathrm{~mL}$ of methanol and $2 \mathrm{~mL}$ of $0.05 \mathrm{M} \mathrm{H}_{2} \mathrm{SO}_{4}$ solution. Afterwards, the cartridge was loaded with the sample and eluted with $2 \mathrm{~mL}$ of distilled water and $2 \mathrm{~mL}$ of methanol to elute the non-basic compounds and dried under vacuum for $5 \mathrm{~min}$ This fraction contained the alkaloid narciclasine,

Table 1. Time interval of detection of the alkaloids based on the monitoring of the $\mathrm{m} / \mathrm{z}$ from their quantitative ions in positive ionization mode (UPLCQDA-SIM)

\begin{tabular}{|c|c|c|c|c|}
\hline Analyte & Molecular formula & time / min & {$[\mathrm{M}+\mathrm{H}]^{+}$} & Time interval / $\mathrm{min}$ \\
\hline Galantamine & $\mathrm{C}_{16} \mathrm{H}_{17} \mathrm{NO}_{4}$ & 2.96 & 288.1 & $2.5-3.5$ \\
\hline Pseudolycorine & $\mathrm{C}_{16} \mathrm{H}_{19} \mathrm{NO}_{4}$ & 2.22 & 290.1 & $1.6-2.6$ \\
\hline Sanguinine & $\mathrm{C}_{16} \mathrm{H}_{19} \mathrm{NO}_{3}$ & 2.12 & 274.1 & $1.6-2.6$ \\
\hline Narciclasine & $\mathrm{C}_{14} \mathrm{H}_{12} \mathrm{NO}_{7}$ & 4.45 & 308.0 & $4.0-5.0$ \\
\hline
\end{tabular}


which is not retained on the cartridge like other alkaloids because of its non-basic amidic nitrogen. ${ }^{26}$ The elution of the further alkaloids was performed by adding $8 \mathrm{~mL}$ of a basic solution $\mathrm{NH}_{4} \mathrm{OH} /$ methanol $\left(25: 75, \mathrm{v} \mathrm{v}^{-1}\right)$. All alkaloidal solutions were filtered through a $0.22 \mu \mathrm{m}$ PTFE filter membrane prior to UPLC-ESI-MS analysis.

\section{Sample preparation}

The alkaloid fractions from Amaryllidaceae plants were obtained through the extraction method III according to the procedure described above.

\section{Validation method}

The validation method was established in agreement with the International Conference on Harmonization (ICH) protocols, ${ }^{27}$ which recommends basically these performance parameters: linearity, recovery, precision (intraday and interday) and limits of detection (LOD) and quantification (LOQ). The MS detector-based selectivity was evaluated by analyzing blank samples and samples fortified with mixed standard solutions of galantamine, pseudolycorine, sanguinine and narciclasine.

\section{Matrix effect}

The matrix effect was determined based on a method described previously by Choi et al. ${ }^{28}$ using a solution of $H$. elegans spiked with the deuterated internal standard codeine- $d_{3}$. This compound was chosen because of its isoquinoline skeleton, which is also found in the analytes, therefore it exhibits similar analytical response. Additionally, codeine- $d_{3}$ must be susceptible to the same interactions of the alkaloidal constituents with the biological matrix, but absent in the sample. Briefly, $0.5 \mathrm{~mL}$ of codeine- $d_{3}$ at $10 \mu \mathrm{g} \mathrm{mL}^{-1}$ was added to an aliquot of $0.5 \mathrm{~mL}$ of the solution $H$. elegans (matrix) eluted from the SPE cartridge as well as to $0.5 \mathrm{~mL}$ of metanol (blank). Next, both mixtures were filled up $50 \mathrm{~mL}$ of methanol. The matrix effect was calculated by the ratio of the difference between the peak areas of codeine- $d_{3}$ in the matrix and in the blank by its peak area in the blank. The matrix effect was expressed in percentage.

\section{Linearity}

The analytical calibration curves were constructed from the mixed solution of $10 \mu \mathrm{g} \mathrm{mL}^{-1}$ alkaloids by diluting at the following concentrations: $1,5,10,25,50,75,100$, $150,200,250,350,400,500,750,1000,1250,1500$ and $2000 \mathrm{ng} \mathrm{mL}^{-1}$. Each standard solution was injected three times into the chromatographic system under the conditions described above. The choice of the points of the calibration curves for each analyte was defined by homoscedasticity of the data, taking into account the Hartley $F$ test and the residue graph. The values of $F_{\text {calculated }}$ were obtained by equation $1 . .^{27}$

$F_{\text {calculated }}=\mathrm{S}_{\max }^{2} / \mathrm{S}_{\min }^{2}$

where $\mathrm{S}_{\max }^{2}$ and $\mathrm{S}_{\min }^{2}$ are the largest and smallest variances for the calibration data, respectively. In order that their numerical values are not significantly different, the value of $F_{\text {calculated }}$ must be less than the critical value corresponding to the same number of degrees of freedom at the known confidence level, critical values were obtained from tabulated values at a confidence level of $99 \%$ for $\mathrm{n}-1$ degrees of freedom, indicating that the regression residues are homoscedastic. Once this assumption is satisfied, it is concluded that there is no evidence of lack of fit to the linear model, hence the model can be considered satisfactory. ${ }^{29}$

As important as making the Hartley $F$ test is carefully examining the residue left by the model. In a well-adjusted model, these residues should have a normal distribution. The residues were calculated by equation 2 , given by the difference between the standard deviations from the experimental signal $\left(\mathrm{S}_{\mathrm{exp}}\right)$ and the interpolated signal $\left(\mathrm{S}_{\text {int }}\right)$ from the regression equation. The residues were plotted against the concentrations of the analytical curves..$^{29,30}$

$\mathrm{R}=\mathrm{S}_{\mathrm{exp}}-\mathrm{S}_{\text {int }}$

With a well-adjusted model, one can do the analysis of variance to test the statistical significance of the linear regression equation. A good way to evaluate this is by comparing the mean of the quadratic sum variance explained in the model $\left(\mathrm{S}_{\text {reg }}^{2}\right)$ by the average quadratic sum of the residue $\left(\mathrm{S}_{\mathrm{r}}^{2}\right)$. Thus, the greater $\mathrm{S}_{\text {reg }}^{2}$ in relation to $\mathrm{S}_{\mathrm{r}}^{2}$, the better the model. The $F$ test to evaluate the significance of the linear regression given by equation 3 must have at least about ten times the value of the point of distribution $F$ (tabulated) with an appropriate number of degrees of freedom (20), at the chosen confidence level (95\%)..$^{27,29}$

$F_{\text {calculated }}=\mathrm{S}_{\text {reg }}^{2} / \mathrm{S}_{\mathrm{r}}^{2}$

After the aforementioned procedure, the calibration curves were composed of the following concentrations: 50, $100,200,500,750$ and $1000 \mathrm{ng} \mathrm{mL}^{-1}$ for galantamine; 100 , 200, 500, 750, 1000 and $1250 \mathrm{ng} \mathrm{mL}^{-1}$ for sanguinine; 75, $100,250,500,750$ and $1000 \mathrm{ng} \mathrm{mL}^{-1}$ pseudolycorine, and $350,400,500,750,1000$ and $1250 \mathrm{ng} \mathrm{mL}^{-1}$ for narciclasine. 


\section{Precision and recovery}

The precision of the method was evaluated in terms of repeatability (intraday) and intermediate (interday) precisions that were conducted in a similar way to the repeatability studies, however, the analysis were conducted by two different analysts in two successive days, analyzing the standard mixture in three concentrations levels: $100 \mathrm{ng} \mathrm{mL}^{-1}$ (lowest level), $500 \mathrm{ng} \mathrm{mL}^{-1}$ (intermediate level) and $1000 \mathrm{ng} \mathrm{mL}^{-1}$ (highest level) in five successive measurements under the same conditions. The standard deviations of repeatability (SD) and the coefficients of variation $(\mathrm{CV} \%)$ for each analyte were calculated according to equations 4 and 5 , respectively. ${ }^{26}$

The recovery was determined by the standard addition assay using a matrix of $H$. elegans devoid of the target alkaloids that was obtained previously after exhaustive extraction (blank). The galantamine, sanguinine, pseudolycorine and narciclasine alkaloids were added at three concentration levels: $100 \mathrm{ng} \mathrm{mL}^{-1}$ (low); $500 \mathrm{ng} \mathrm{mL}^{-1}$ (intermediate) and $1000 \mathrm{ng} \mathrm{mL}^{-1}$ (high) in five independent replicates. The values of the coefficients of variation must be within the acceptable limits for recovery (80 to 120 $\mathrm{CV} \%)$. The recovery was calculated by equation $6 .{ }^{31}$

$\mathrm{SD}=\sqrt{\frac{\left(\mathrm{x}_{\mathrm{i}}-\overline{\mathrm{x}}\right)^{2}}{(\mathrm{n}-1)}}$

$\mathrm{CV}(\%)=\frac{\mathrm{SD}}{\mathrm{xX}} \times 100$

Recovery $(\%)=\left(\frac{\mathrm{C}_{1}-\mathrm{C}_{2}}{\mathrm{C}_{3}}\right) \times 100$

where $\mathrm{x}_{\mathrm{i}}$ is the value for each concentration in each replicate for concentration level $\mathrm{i}, \mathrm{X}$ is the mean concentration value at a given level $\mathrm{i}, \mathrm{n}$ is the number of replicates at each level and SD is the standard deviation of repeatability. The repeatability conditions and the coefficient of variation shall be less than two-thirds of the values according to the concentration range. $C_{1}$ is the concentration of the analyte in the fortified sample, $\mathrm{C}_{2}$ concentration of the analyte in the non-fortified sample and $\mathrm{C}_{3}$ concentration of the analyte added to the fortified sample. ${ }^{30}$

\section{Limits of detection and quantification}

The limits of detection (LOD) and of quantification (LOQ) were established by successive dilutions of the mixed standard solution up to the lowest detectable level that resulted in the signal-to-noise ratio $(\mathrm{S} / \mathrm{N})$ of $3: 1$ and $10: 1$, respectively. ${ }^{27}$

\section{Results and Discussion}

\section{Development of the chromatographic method by UPLC- QDA-SIM}

The present study showed the efficiency of the UPLC-QDA-SIM method for the quantification of the alkaloids galantamine, sanguinine, pseudolycorine and narciclasine simultaneously. Firstly, the sample preparation was evaluated by testing three extraction procedures at room temperature: (I) acid-base liquid-liquid partition (II) solidliquid extraction and (III) solid-liquid extraction followed by solid-phase extraction. This latter was chosen for yielding extracts with higher alkaloids contents (based on their peak areas) and fewer interfering compounds as can be seen on their UPLC-QDA chromatograms (Figures S2 and S3, SI section). In fact, samples cleaned up by SPE enable more reproducible analysis and less susceptible to matrix effect, besides extending the lifetime of the chromatographic system. ${ }^{32}$ The cation exchange SPE cartridges retain selectively positively charged molecules of the alkaloid due to the ionization of its basic nitrogen in acid medium. This strategy seems to be particularly useful when the alkaloids of interest are not abundant or the availability of plant material is limited. ${ }^{33}$

Also, the chromatographic separation of the alkaloids was optimized with respect to the sample temperature (10 and $20^{\circ} \mathrm{C}$ ), injection volume (2 and $\left.5 \mu \mathrm{L}\right)$ and column temperature $\left(30,40\right.$ and $\left.50{ }^{\circ} \mathrm{C}\right)$. The sample temperature and injection volume sample did not affect the chromatographic response. On the other hand, the column temperature showed a deleterious effect. Runs at $30^{\circ} \mathrm{C}$ were longer, while those at $50{ }^{\circ} \mathrm{C}$ resulted in decreased peaks likely due to thermal degradation. Thus, taking into account the most amenable conditions, the best result was achieved for a run time of $10.5 \mathrm{~min}$ by injecting $2 \mu \mathrm{L}$ of sample at $20{ }^{\circ} \mathrm{C}$ into the column maintained at $40{ }^{\circ} \mathrm{C}$.

Validation of the UPLC-MS method for quantification of alkaloids

Afterwards, the UPLC-QDA-SIM method was validated. Its selectivity can be evidenced through the chromatograms of the mix of alkaloid standards and samples from Amaryllidaceae species extracts (Figure S4, SI section), which exhibit well-resolved peaks for the preselected $\mathrm{m} / \mathrm{z}$ ions in their respective time intervals.

\section{Matrix effect}

The value calculated for the matrix effect was of $13.1 \%$. According to the literature, values lower than $20 \%$ reveal 
that the matrix effect is not significant. ${ }^{28}$ This result may be at least in part attributed to the high dilution factor of the sample (100-fold). Therefore, the behavior of the analyte in the plant matrix approached that in the solvent.

\section{Linearity}

The good linearity was determined by the correlation coefficients $(\mathrm{R})$ of the four calibration curves greater than 0.9968 and endorsed by Hartley $F$ and homoscedasticity tests (Table 2). The Hartley $F$ test revealed that there is no evidence of a lack of fit of the linear models, given the low values of $F_{\text {calculated }}$ versus $F_{\text {critic }}\left(F_{\text {calculated }}<F_{\text {critic }}\right)$ (Table 2$)$. Furthermore, in a well-adjusted model, the residues should exhibit a normal distribution in which the residues vary independently of the concentration. Thus, a random distribution of the residues, where their variance can be considered constant, indicates the homoscedasticity of the model. ${ }^{29}$ From the analysis of the residual graphs (Figure S5, SI section), it was verified the random behavior of the residues around the concentration axis. Additionally, the errors of the calibration parameters, confidence intervals and predictions from the regression equations were estimated. The indication of a linear relationship between the variables $x$ and $y$ was highly significant for all alkaloids, given the high value of $F_{\text {calculated }}$. Since we have assumed that errors are distributed normally, the Student distribution could be used to test the significance of the estimated value for the angular coefficient and the intercept. The statistical analysis for the parameters of the analytical curves (Table 2) unveiled that all slopes are significant $\left(t_{\text {calculated }}<t_{\text {tabulated }}\right)$ and none of the intercepts present statistical significance $\left(t_{\text {calculated }}<t_{\text {tabulated }}\right) .^{29}$

\section{Accuracy and precision}

The method showed to be reliable and reproducible based on the results obtained for recovery, repeatability and intermediate precision, which were expressed as percentage and coefficients of variation (CV\%) in Table 3. All outcomes were within the acceptable limits for recovery $(87.5-96.2 \%)$ except for narciclasine $(70.5 \%)$. Likewise, all mean values for intraday (1.3-8.4\%) and interday precisions were satisfactory $(5.7-8.1 \%)$ at the three levels of concentration, however narciclasine had a slightly decreased interday precision (12.9\%). ${ }^{27}$ The low recovery and reproducibility for narciclasine may be related to its poor retention into the SPE cartridge, which varies depending on the $\mathrm{pH}$.

\section{Limits of detection and quantification}

Our UPLC-MS method showed to be highly sensitive thanks mainly to the use of the SIM mode. The results for LOD and LOQ ranged from 5-100 and 20-350 $\mathrm{ng} \mathrm{mL}^{-1}$, respectively, as can be seen in Table 3. The lowest LOD and LOQ were achieved for galantamine, 5 and $20 \mathrm{ng} \mathrm{mL}^{-1}$ respectively. To the best of our knowledge, the most sensitive LC method for galantamine in plant materials

Table 2. Statistical data of the four alkaloid analytes: calibration curves, correlation coefficients (r), linearity, range, $t_{\text {calculated }}$ in relation to the slope (b) and intercept (a) for a $t_{\text {tabulated }}$ of $0.68 ; F$ of significance of the linear regression and $F_{\text {critical }}$ of the Snedecor's distribution for 1 degree of freedom (DF) at the numerator and $\mathrm{n}-2$ degrees of freedom at the denominator, Hartley $F$ test $\left(F_{\text {Hart }}\right)$ and the Hartley's tabulated value $\left(F_{\text {tab }}\right)$. All tests were performed at a significance level of $5 \%$

\begin{tabular}{|c|c|c|c|c|c|c|c|c|c|}
\hline \multirow{2}{*}{ Analyte } & \multirow{2}{*}{ Calibration curve } & \multirow{2}{*}{$\mathrm{r}$} & \multirow{2}{*}{$\begin{array}{c}\text { Linearity / } \\
\left(\mathrm{ng} \mathrm{mL}^{-1}\right)\end{array}$} & \multicolumn{2}{|c|}{$t_{\text {calculated }}$} & \multirow{2}{*}{$F$} & \multirow{2}{*}{$\begin{array}{c}F_{\text {crit }} \\
\text { (DF) }\end{array}$} & \multirow{2}{*}{$F_{\text {Hart }}$} & \multirow{2}{*}{$\begin{array}{l}F_{\text {tab }} \\
\text { (DF) }\end{array}$} \\
\hline & & & & $\mathrm{b}$ & a & & & & \\
\hline Galantamine & $y=399.6 x+16977$ & 0.9986 & $50-1000$ & 79.7 & 12.2 & 13911.0 & $4.17(33)$ & 0.36 & $2.91(33)$ \\
\hline Sanguinine & $y=52.967 x-90.16$ & 0.9987 & $100-1250$ & 54.8 & 16.6 & 9230.7 & $4.17(33)$ & 0.01 & $2.91(33)$ \\
\hline Pseudolycorine & $y=62.037 x+1012.1$ & 0.9978 & $75-1000$ & 24.3 & 17.5 & 5383.1 & $4.35(27)$ & 0.09 & $3.76(27)$ \\
\hline Narciclasine & $y=1.13 x+39.823$ & 0.9968 & $350-1250$ & 21.9 & 10.5 & 2407.8 & $4.17(33)$ & 0.18 & $2.91(33)$ \\
\hline
\end{tabular}

Table 3. Percentage of recovery, coefficients of variation (CV\%) for intraday and interday precisions along with limits of detection (LOD) and quantification (LOQ) from the UPLC-MS method for quantification of four alkaloids $(n=5)$

\begin{tabular}{|c|c|c|c|c|c|c|}
\hline \multirow{2}{*}{ Alkaloid } & \multicolumn{4}{|c|}{ Recovery (intraday and interday precisions, $\mathrm{CV} \%$ ) /\% } & \multirow{2}{*}{$\mathrm{LOD} /\left(\mathrm{ng} \mathrm{mL} L^{-1}\right)$} & \multirow{2}{*}{$\mathrm{LOQ} /\left(\mathrm{ng} \mathrm{mL}^{-1}\right)$} \\
\hline & $100 \mathrm{ng} \mathrm{mL}^{-1}$ & $500 \mathrm{ng} \mathrm{mL}^{-1}$ & $1000 \mathrm{ng} \mathrm{mL}^{-1}$ & Mean CV\% & & \\
\hline Galantamine & $92.3(2.1 ; 5.5)$ & $96.1(1.4 ; 7.1)$ & $100.5(0.3 ; 4.4)$ & $96.2(1.3 ; 5.7)$ & 5 & 20 \\
\hline Pseudolycorine & $84.5(16.0 ; 11.7)$ & $86.2(4.4 ; 4.7)$ & $91.6(5.0 ; 4.6)$ & $87.5(8.4 ; 7.0)$ & 25 & 80 \\
\hline Sanguinine & $89.7(7.1 ; 10.2)$ & $90.3(3.6 ; 8.0)$ & $92.1(1.2 ; 6.0)$ & $90.3(4.0 ; 8.1)$ & 27 & 90 \\
\hline Narciclasine & $62.1(8.7 ; 18.9)$ & $73.0(3.9 ; 8.1)$ & $76.3(11.0 ; 11.7)$ & $70.5(7.9 ; 12.9)$ & 100 & 350 \\
\hline
\end{tabular}


Table 4. Quantification of the alkaloids found in the bulbs of four Amaryllidaceae species ( $n=3)$

\begin{tabular}{lcccc}
\hline \multirow{2}{*}{ Species } & \multicolumn{4}{c}{ Alkaloids / $\left(\mu \mathrm{g} \mathrm{g}^{-1}\right.$ dried bulb) } \\
\cline { 2 - 5 } & Galantamine & Sanguinine & Pseudolycorine & Narciclasine \\
\hline Habranthus cf. irwinianus & $41.7 \pm 0.9$ & ND & $372.6 \pm 28.2$ & ND \\
Hymenocallis littoralis & $39.4 \pm 3.0$ & ND & $409.6 \pm 6.3$ & $219.0 \pm 1.4$ \\
Griffinia nocturna & $79.2 \pm 0.5$ & ND & $358.2 \pm 3.2$ & $418.4 \pm 1.2$ \\
Hippeastrum elegans & $42.9 \pm 3.1$ & $182.3 \pm 5.2$ & $1561.2 \pm 169$ & $768.1 \pm 15.4$ \\
\hline
\end{tabular}

ND: not detected.

had a LOQ of $37 \mathrm{ng} \mathrm{mL}^{-1}$ using a DAD as detector and taking 45 min for quantifying two alkaloids. ${ }^{8}$ Mroczek $^{11}$ developed a HPLC-ESI-MS method for three alkaloids, among them galantamine whose LOD was of $1210 \mathrm{ng} \mathrm{mL}^{-1}$. Katoch et al. ${ }^{10}$ developed a UPLC-DAD method for quantifying four alkaloids from Zephyranthes grandifolia in $8 \mathrm{~min}$, however it was nearly 300 times less sensitive than ours. Also, Gotti et al. ${ }^{6}$ quantified four alkaloids by GC-MS in 30 min, obtaining a LOQ of $6150 \mathrm{ng} \mathrm{mL}^{-1}$. In addition to the aforementioned advantages, our UPLC-MS method is the first report for simultaneous quantification of galantamine, sanguinine, pseudolycorine and narciclasine.

\section{Quantification of alkaloids in Amaryllidaceae}

The validated method was applied for quantification of the alkaloids galantamine, pseudolycorine, sanguinine and narciclasine in bulbs from Habranthus cf. irwinianus, Hymenocallis littoralis, Griffinia nocturna and Hippeastrum elegans. The samples were analyzed in extraction triplicates and their contents $\left(\mu \mathrm{g} \mathrm{g}^{-1}\right.$ dried bulb) are shown in Table 4. Galantamine ranged between $39.4 \pm 3.0$ and $79.2 \pm 0.5 \mu \mathrm{g} \mathrm{g}^{-1}$, while pseudolycorine varied from $358.2 \pm 3.2$ to $1561.2 \pm 169 \mu \mathrm{g} \mathrm{g}^{-1}$, depending on the species. Narciclasine presented contents varying between $219.0 \pm 1.4$ and $768.1 \pm 15.4 \mu \mathrm{g} \mathrm{g}^{-1}$, however, it was not detected in $H$. cf. irwinianus. Sanguinine was found only in $H$. elegans $\left(182.3 \pm 5.2 \mu \mathrm{g} \mathrm{g}^{-1}\right)$. Our work is the first report on quantitation of these alkaloids in the species studied. Furthermore, our quantification method showed to be suitable for analyzing different alkaloids in four Amaryllidaceae genera, using only $100 \mathrm{mg}$ of plant material.

\section{Conclusions}

Our UPLC-ESI-MS method showed good linearity and selectivity, in addition to satisfactory recovery, precision, limits of detection and quantification for the simultaneous analysis of four alkaloids in different Amaryllidaceae plants. Hence, it demonstrated to be rapid, sensitive and reliable for being employed in galantamine-rich plant breeding programs and prospection of new sources of this compound and other bioactive alkaloids.

\section{Supplementary Information}

Graphs and chromatograms used in the selection of the analytical method can be accessed free of charge at http://jbcs.sbq.org.br as PDF file.

\section{Acknowledgments}

The authors thank to Embrapa (SEG 03.14.01.007.00.00) for the financial support and to CAPES for a DSc scholarship granted to the author J. R. de Paiva. The authors are grateful to Andrielle Camara Amaral Lopes (Embrapa Recursos Genéticos) for providing Amaryllidaceae bulbs to collection grown at the Embrapa Agroindústria Tropical field.

\section{References}

1. Marco-Contelles, J.; Carreiras, M. C.; Rodríguez, C.; Villarroya, M.; García, A. C.; Chem. Rev. 2006, 106, 116.

2. Ago, Y.; Koda, K.; Takuma, K.; Matsuda, T.; J. Pharmacol. Sci. 2011, 116, 6 .

3. Berkov, S.; Georgieva, L.; Kondakova, V.; Atanassov, A.; Viladomat, F.; Bastida, J. C. C.; Biotechnol. Biotechnol. Equip. 2009, 23, 1170.

4. Hermann, A. M.; Future Sci. OA 2015, 4.

5. Conforti, F.; Loizzo, M. R.; Marrelli, M.; Menichini, F.; Statti, G. A.; Uzunov, D.; Menichini, F.; Pharm. Biol. 2010, 48, 2.

6. Gotti, R.; Fiori, J.; Bartolini, M.; Cavrini, V.; J. Pharm. Biomed. Anal. 2006, 42, 17.

7. Khonakdari, M. R.; Mirjalili, M. H.; Gholipour, A.; Rezadoost, H.; Farimani, M. M.; Plant Genet. Resour. 2018, 16, 188.

8. Emir, A.; Önür, M. A.; Marmara Pharm. J. 2016, 20, 320.

9. Abou-Donia, A. H.; Toaima, S. M.; Hammoda, H. M.; Shawky, E.; Phytochem. Anal. 2008, 19, 353. 
10. Katoch, D.; Kumar, S.; Kumar, N.; Singh, B.; J. Pharm. Biomed. Anal. 2012, 71, 187.

11. Mroczek, T.; J. Chromatogr. A 2009, 2519.

12. Guoa, Y.; de Andrade, J. P.; Torras-Claveria, N. B. P. L.; Tallini, L. R.; Borges, W. S.; Viladomat, F.; Nair, J. J.; Zuanazzi, J.A. S.; Bastida, J.; Helv. Chim. Acta 2016, 99, 143.

13. Svinyarov, I.; Keremedchieva, R.; Bogdanov, M. G.; Sep. Sci. Technol. 2016, 51, 2691.

14. Tian, Y.; Zhang, C.; Guo, M.; Molecules 2015, 20, 21854.

15. Zhao, Y. Y.; Cheng, X. L.; Vaziri, N. D.; Liu, S. L. R.; Clin. Biochem. 2015, 47, 16.

16. Wang, J.; Pavurala, N.; Xu, X.; Krishnaiah, F. P.; Biomed. Chromatogr. 2018, 32, 4275

17. Yao, C.; Yang, W.; Si, W.; Pan, H.; Qiu, S.; Wu, J. G. D.; RSC Adv. 2016, 69, 65055.

18. Rodrigues, K.; Julião, G.; de Cássia, R.; Pereira, A.; Itana, F.; Custódio, C.; Riceli, P.; Ribeiro, V.; Sousa, E.; Brito, D.; Rocha, E.; Marques, K.; J. Pharm. Biomed. Anal. 2019, 166, 155.

19. Yao, C.; Yang, W.; Si, W.; Pan, H.; Qiu, S.; Wu, J.; Shi, X.; Feng, R.; Wu, W.; Guo, D.; RSC Adv. 2016, 6, 65055.

20. He, M.; Qu, C.; Gao, O.; Hu, X.; Hong, X.; RSC Adv. 2015, 5 , 16562.

21. Fürst, R.; Planta Med. 2016, 82, 1389.

22. Carvalho, K. R.; Silva, A. B.; Torres, M. C. M.; Pinto, F. C. L.; Guimarães, L. A.; Rocha, D. D.; Silveira, E. R.; Costa-Lotufo, L. V.; Braz-Filho, R.; Pessoa, O. D. L.; J. Braz. Chem. Soc. 2015, 26, 1976.

23. Empower ${ }^{\circledR}$ 3; Waters Corporation, Milford, USA, 2017.
24. Luz, R.; Porto, D. D.; Castro, C. B.; Silva, F. S.; Godoy, A. F. A.; J. Chromatogr. B 2018, 1099, 97.

25. Reinwaldt, C.; Bittner, M.; Kempe, G.; Glauner, T.; Agilent Technologies, Inc., available at https://www.agilent.com/cs/ library/applications/5991-7301EN.pdf, accessed in July 2019.

26. Kornienko, A.; Evidente, A.; Chem. Rev. 2008, 6, 1982.

27. Harmonised Tripartite Guideline Text on Validation of Analytical Procedures: Text and Methodology, available at https://www. ich.org/fileadmin/Public_Web_Site/ICH_Products/Guidelines/ Quality/Q2_R1/Step4/Q2_R1__Guideline.pdf, accessed on December 13, 2018.

28. Choi, S.; Kim, S.; Young, J.; Kim, M.; Kim, J.; Food Chem. 2015, 173, 1236.

29. Miller, J.; Miller, J. C.; Statistics and Chemometrics for Analytical Chemistry, $6^{\text {th }}$ ed.; Pearson Higher Education: London, England, 2018.

30. Silva, C. P.; Emídio, E. S.; Marchi, M. R. R.; Talanta 2015, $131,221$.

31. González, A. G.; Herrador, M. A.; TrAC, Trends Anal. Chem. 2007, 26, 227.

32. Chambers, E.; Wagrowski-Diehl, D. M.; Lu, Z.; Mazzeo, J. R.; J. Chromatogr. B 2007, 852, 22.

33. da Silva, L. F.; Guerra, C. C.; Klein, D. B. A.; Food Chem. 2017, $227,158$.

Submitted: February 23, 2019

Published online: July 16, 2019 